\title{
Self- esteem Among Male and Female Nursing Students Enrolled in Maternity Curriculum- Assiut University
}

\author{
Aisha Abd-Elnaser Fawzy ${ }^{1}$, Hosnia Shehata Mohamed ${ }^{2,}$ Heba Mostafa Mohamed $^{3}$, Safaa Rashad Mahmoud ${ }^{4} \&$ \\ Nabila Taha Ahmed 5 . \\ 1. Clinical instructor, Department of Maternal \&Newborn Health Nursing, Faculty of Nursing, Assiut University, \\ Egypt. \\ 2. Lecturer of Psychiatric \& Mental Health Nursing, Faculty of Nursing, Assiut University, Egypt. \\ 3. Lecturer of Obstetrics \& Gynecological Nursing, Faculty of Nursing, Assuit University, Egypt. \\ 4. Assistant professor of Community Health Nursing, Faculty of Nursing, Assiut University, Egypt. \\ 5. Professor of Obstetrics \& Gynecological Nursing, Faculty of Nursing, Assuit University, Egypt.
}

\begin{abstract}
Background: The complex nature of nursing and midwifery as professions, and the challenges for students to achieve competencies to meet their profession's clinical and academic requirements all of this factors may have a negative effect on students' self-esteem. Aim: The study aims to assess the level of self-esteem among male and female nursing students enrolled in maternity curriculum, at Assiut University. Methods: Purposive sample of 475; (172 male and 303 female), third year nursing students, Faculty of Nursing, Assuit University were enrolled. Descriptive design was used in this study, two tools were used for this study; personnel data sheet and Eldesoky selfesteem scale (2004). Results: The study findings revealed that both female nursing students and male nursing students had moderate level of self-esteem (42\% and $43 \%$ ) respectively, and also there are statistically significant difference between levels of self-esteem and "family residency and pre-university qualifications. Conclusion: The present study concluded that there were no differences in self-esteem levels between males and females nursing student. Recommendations: The study recommended incorporating self-esteem-related teaching activities into the existing curriculum to improve students' self-esteem. furthers studies must be done to generalize the results.
\end{abstract}

\section{Key Words: Self-esteem, Nursing Students \& Maternity Curriculum.}

\section{Introduction}

Self-esteem is one of the most important factors for progress, talent and creativity development, it penetrates all ideas, perceptions, excitements, dreams, values and goals of an individual. It is defined as how people think about themselves and how they feel about themselves in their social and academic life and how close and synchronized their own ideal self and actual self (Alavijeh, et al., 2018).

Self-esteem refers to an individual's subjective evaluation of his or her worth as a person, the development of self-esteem is characterized by progressive increase from adolescence to adulthood and peak around 50 to 60 years of age, then it decreases in the old age (Hank, \& Baltes-Götz, 2019). High levels of self-esteem are predictive of good outcomes in domains such as academic achievement, social life, physical and mental health, satisfaction with marriage and Job. But low level of self-esteem implies self-rejection, self-dissatisfaction, and self-contempt, as the individual lacks respect for the self (Silvestri, et al., 2018).

Self-esteem is by no means an immutable characteristic of individuals. People experience changes in their self-esteem, both in terms of temporary boosts or drops in their feelings of self- worth and in terms of long-term increases or declines in their general level of self-esteem. For example, successes at school, work conflicts, or harmonious family events may cause transient fluctuations in selfesteem (Orth U., et al., 2018).

Self-esteem as being the sum of an individual's achievements divided by what they think they ought to achieve. Self-esteem can be increased by achieving great successes and maintained by avoiding failures. High self-esteem related highly to self-reported happiness which may increase from a feeling of competence, confidence, goal-directedness, and selfefficacy which may lead to having good score in exams (D'Mello, et al., 2018).

The complex nature of nursing and midwifery as professions, the ongoing changes in the healthcare system and the challenges for students to achieve competencies to meet their profession's clinical and academic requirements all of this factors may have a negative effect on students' self-esteem (McCarthy, et al., 2018).

Low self-esteem has been associated with negative outcomes, such as depression, anxiety, and anger, as well as aggressive and violent behaviors, this is due to individuals with low self-esteem may display aggression to avoid the humiliation and feelings of 
inferiority brought about by failure in an attempt to improve their self-esteem (Teng Z., et al., 2015). Sociometer theory reported that self-esteem is a result of being accepted or not accepted by others. Accordingly, self-esteem serves two functions: to have social acceptance, and to prompt affiliative behavior. While hierometer theory proved that it is a result of a level of social status, and its functions are to track one's social status and to regulate assertive behavior (Bialobrzeska, et al., 2018). Another theory proposed that self-esteem is generally explained as the individual's general attitude towards, or assessment of the self, and it reflects people's beliefs about how worthy they are as persons and if they merit respect, it is also seen as the central evaluative component of the self and it is considered as a fundamental psychological construct (Von Soest, et al., 2016).It is also among various personal beliefs that are vital when it comes to the evaluation of environmental demands. While evaluating the external demands they are being observed as either "threat", or a "challenge." Although, persons with low level of self-esteem consider these demands as threats while those with high level of self-esteem evaluate these demands as a challenge (Farhan \& Khan, 2015).

\section{Significance of the study}

Self-esteem in nursing is a fundamental part of personal and professional identity. Student nurses today are the nucleus of professional nurses of tomorrow, so it is crucial for faculty student nurses to be individuals with high self-esteem in order to ensure competent and safe practice (Velmurugan , et al., 2018). Despite the core role that self-esteem plays in the identity of nursing students and nurses, there is a distinct lack of research on the topic. In Egypt a study was done in 2016 at faculty of nursing at Mansoura university and it showed that only 3.3\% of nursing students had a high level of self-esteem. (Hanafi, et al., 2015).

Having knowledge of nursing students' levels of understanding about the nature of self-esteem would enable academics to plan and implement practical steps to help student nurses enhance their self-esteem. For this, it is necessary to explore the concept of selfesteem and identify factors which limit or enable development of this concept in nursing students. (Zamanzadeh, et al., 2016).

Male nursing students are faced with more challenges in the clinical environment than their female counterparts. The ways in which male nurses are viewed and received by nursing staff and patients have an impact on how they perceive themselves and their role in the profession. These perceptions of self- have a significant impact on their self-esteem. (Buthelezi, et al., 2015). Subjects and methods

\section{Aim of the study}

The study aims to assess the level of self-esteem among male and female nursing students enrolled in maternity curriculum, at Assiut University.

\section{Research questions}

- What is the level of self-esteem among male and female nursing students enrolled in maternity curriculum, Assiut University?

- Does self-esteem differs between male and female nursing students enrolled in maternity curriculum?

\section{Study design}

Descriptive design was used in the current study.

Setting

This study was implemented at the Maternal and Newborn Health Nursing labs and classes, Faculty of Nursing, Assuit University. It is governmental educational institution which offer bachelor degree in nursing science.

\section{Study participants}

Purposive sample; of the third year nursing students (male and female) who had studied maternity nursing curriculum in the first and second semester of academic year 2018-2019, the total coverage number of students was 475, (172 males and 303 female).

\section{Inclusion criteria}

- Nursing students enrolled in maternity curriculum.

-Nursing students who accept to participate in the study.

Tools of the study

Two tools were used for this study:

Tool 1

Personal data sheet, which developed by the investigator after reviewing the related literatures it contains: age, gender, marital status, students' residence, as well as their pre-university qualification (Secondary school- Technical Institute of Health/Nursing) previous academic year achievement, students' residence during current academic year.

Tool 2

Self Esteem Scale: Self-esteem was assessed through using El-desoky self-esteem scale (2004); this scale consisted of 25 statements about the positive and negative sensation of self-worth for example:

1. I feel that I have a number of good qualities.

2. I feel like a nice I feel person.

3. I feel that others will not like me if they realize or know my truth.

4. Ifeel like a boring person.

5. I feel I need more confidence. 


\section{Scoring system}

The scale contains 12 positive statements and 13 negative statements, scored on four-point Likert type scale ranging from "never" to all the time" Each scoring response is classified to 1-4 degrees. 1 degree is assigned for never, 2 degrees for rare, 3 degrees for sometimes, and 4 degrees for all the time. In total score of 100.

1- Scores less than 50 indicates high (positive) selfesteem.

1. Scores from 50 to 57 indicates moderate selfesteem.

2- Scores of 57 and more indicates low(negative) self-esteem.

Validity \& reliability of the tools

Validity of the tool was done, before actual study work through a jury panel of five experts in the field of maternity and psychiatric nursing, whilst the reliability was assessed by measuring its internal consistency using, Alpha Cronbach's test for the tool.

\section{Procedures}

\section{Administrative phase}

an official approval was obtained to carry out the study from the dean of the Faculty of Nursing, Assuit University.

\section{Ethical consideration}

Research proposal was approved from ethical committee in the Faculty of Nursing. Informed consent was obtained from students who were participated in the study, after explaining the nature and purpose of the study. There was no any risk for the students during conduction of the study. The study was followed common ethical principles in clinical research. Confidentiality and anonymity would be assured and the participating students had the right to refuse participation or withdraw from the study without any rational.

\section{Pilot study}

A pilot study was carried out after preparation and revision of the study tools for validation by supervisors and before starting the data collection on $10 \%$ (48students) of students to test the clarity and feasibility of the study tools. After conducting a pilot study there weren't any modification on the tools and so the sample of the pilot study was included in the total sample.

\section{Actual Phase}

All nursing students enrolled in maternity curriculum accepted to participate in the study. Students was informed that completion of the study will be completely voluntary. After the students have finished their theoretical course and their clinical training, and before the final exam the investigator divided students into groups, each group included 15 -20 students. The investigator meeting them in the
Maternal and Newborn Health Nursing labs and classes twice weekly for about 24 sessions, after finishing their study, then great the students and introduce herself (as an investigator of the current study), provide an explanation of the study including its purpose, use of results and anonymity of the tools, (maintain confidentiality). The investigator distributed the tools to the participants to obtain the necessary data. Each group take about 15 minutes to filling the tools. The investigator stays with the participants to the end of the session, to answer any questions that students may ask. After that the investigator collects the tools from the students and thanking them for their participation in this study. Reviewing the collected tools to make sure of its completeness.

The data collection started from first of December, 2018 to the end of April ,2019 (5 months).

\section{Statistical analysis}

Data analysis was performed using SPSS 20 statistical software. The qualitative variables were described using frequency and percentages, and quantitative variables were described using range, mean, and standard deviation. Chi-square test was used; independent t-test was also. $\mathrm{P}$ value $<0.05$ was considered as the significance level. 


\section{Results}

Table (1): Distribution of the maternity nursing students according to their personal data $(n=475)$.

\begin{tabular}{|c|c|c|}
\hline Personal data & No. & $\%$ \\
\hline \multicolumn{3}{|l|}{ Age (years): } \\
\hline - $\quad$ Range & \multicolumn{2}{|c|}{$20-23$} \\
\hline $\mathrm{M} \pm \mathrm{SD}$ & \multicolumn{2}{|c|}{$20.91 \pm .699$} \\
\hline \multicolumn{3}{|l|}{ Gender: } \\
\hline - $\quad$ Male & 172 & 36.2 \\
\hline - $\quad$ Female & 303 & 63.8 \\
\hline \multicolumn{3}{|l|}{ Marital status } \\
\hline - $\quad$ Single & 466 & 98.1 \\
\hline - $\quad$ Married & 9 & 1.9 \\
\hline \multicolumn{3}{|l|}{ Students' family residence } \\
\hline - $\quad$ Rural & 299 & 62.9 \\
\hline - Urban & 176 & 37.1 \\
\hline \multicolumn{3}{|c|}{ Students' residence during current academic year. } \\
\hline - $\quad$ With family & 174 & 36.6 \\
\hline - University campus & 243 & 51.2 \\
\hline - $\quad$ External housing & 58 & 12.2 \\
\hline \multicolumn{3}{|l|}{ pre-university qualification } \\
\hline - $\quad$ Secondary school & 407 & 85.7 \\
\hline - $\quad$ Technical Institute of Health/Nursing & 68 & 14.3 \\
\hline \multicolumn{3}{|l|}{ previous academic year achievement } \\
\hline - $\quad$ Excellent & 92 & 19.4 \\
\hline - $\quad$ Very good & 269 & 56.6 \\
\hline - $\quad$ Good & 105 & 22.1 \\
\hline - $\quad$ Satisfactory & 9 & 1.9 \\
\hline Total & 475 & 100 \\
\hline
\end{tabular}

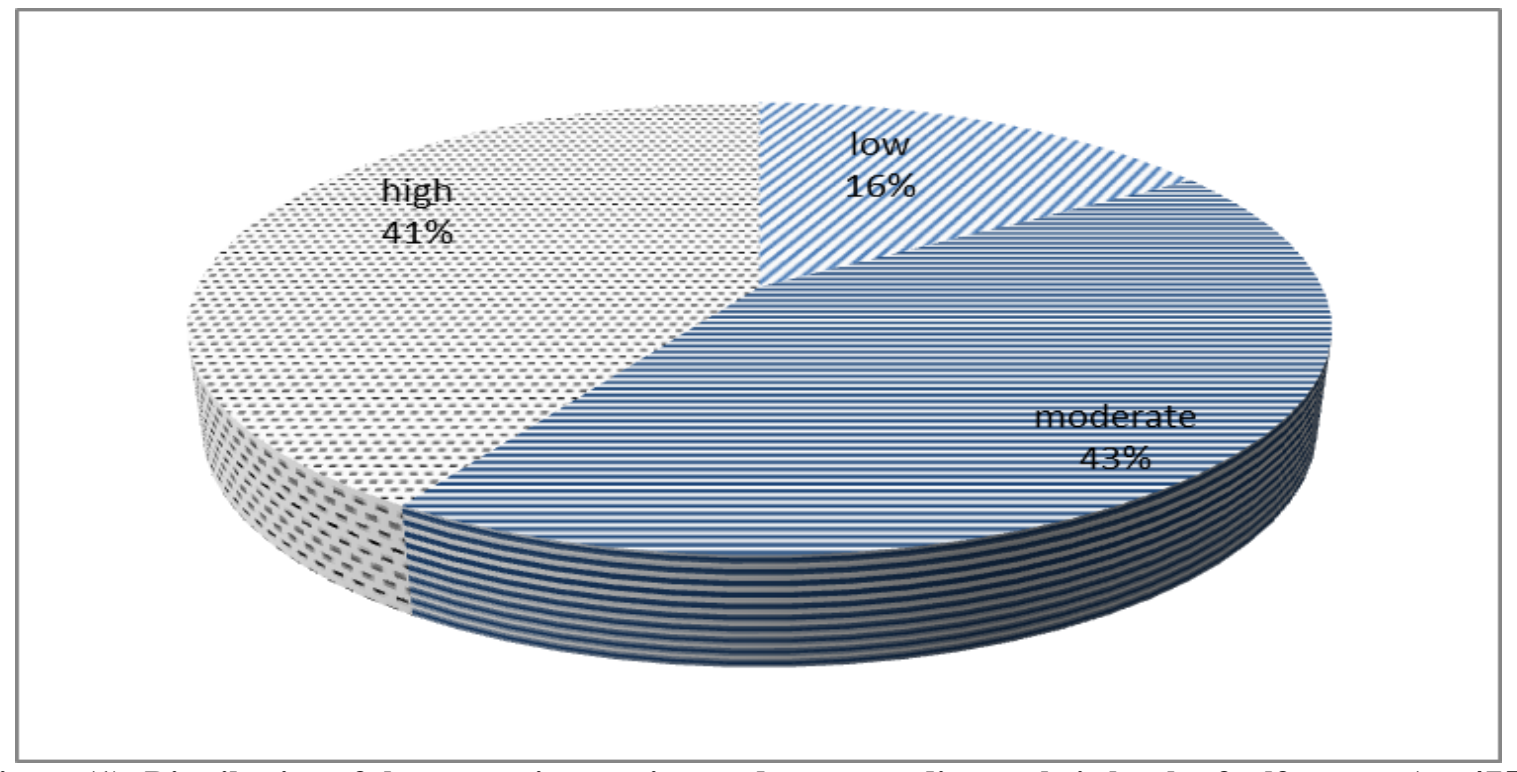

Figure (1): Distribution of the maternity nursing students according to their levels of self-esteem $(n=475)$. 


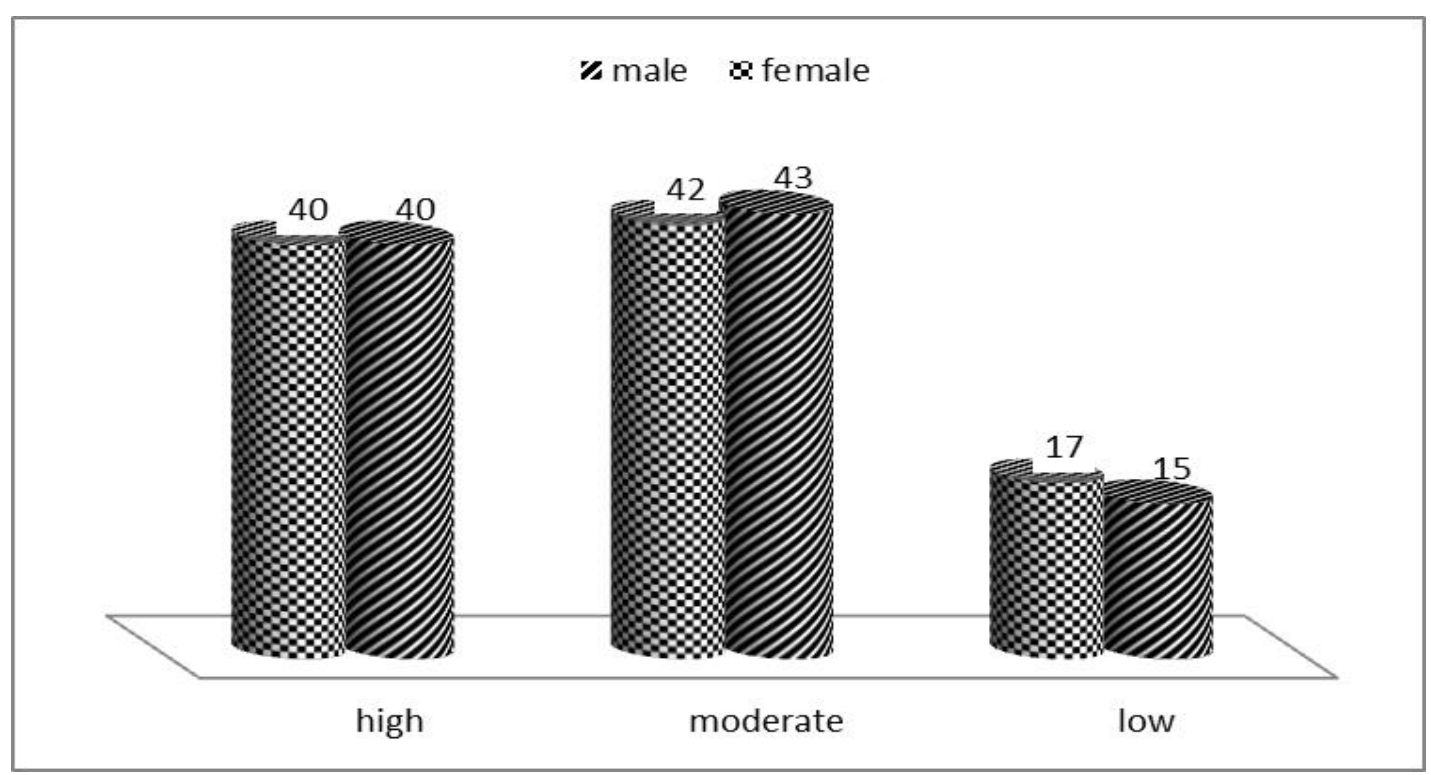

Figure (2): Distribution of the maternity nursing students according to their levels of self-esteem regarding their gender $(n=475)$.

Table (2): Relation between maternity nursing students' self-esteem level and their personal data $(n=475)$.

\begin{tabular}{|c|c|c|c|c|c|c|c|c|c|}
\hline \multirow{3}{*}{ personal data } & \multicolumn{6}{|c|}{ Self-esteem } & \multirow{3}{*}{ Total } & \multirow{3}{*}{$\mathbf{X} 2$} & \multirow{3}{*}{$\begin{array}{c}\text { p- } \\
\text { value }\end{array}$} \\
\hline & \multicolumn{2}{|c|}{ Low } & \multicolumn{2}{|c|}{ Moderate } & \multicolumn{2}{|c|}{ High } & & & \\
\hline & No & $\%$ & No & $\%$ & No & $\%$ & & & \\
\hline \multicolumn{10}{|l|}{ Age (years): } \\
\hline - $\quad$ Range $20-23$ & \multicolumn{2}{|c|}{$20.85 \pm .681$} & \multicolumn{2}{|c|}{$20.96 \pm .728$} & \multicolumn{2}{|c|}{$20.8 \pm .675$} & 475 & - & .339 \\
\hline \multicolumn{10}{|l|}{ Gender: } \\
\hline - $\quad$ Male & 28 & $15.8 \%$ & 75 & $43.9 \%$ & 69 & $40.4 \%$ & 172 & \multirow{2}{*}{.166} & \multirow{2}{*}{.920} \\
\hline - $\quad$ Female & 52 & $17.1 \%$ & 129 & $42.4 \%$ & 122 & $40.5 \%$ & 303 & & \\
\hline \multicolumn{10}{|l|}{ Marital status } \\
\hline - $\quad$ Single & 76 & $16.3 \%$ & 200 & $42.9 \%$ & 190 & $40.8 \%$ & 466 & \multirow{2}{*}{2.29} & \multirow{2}{*}{.351} \\
\hline - $\quad$ Married & 3 & $33.3 \%$ & 4 & $44.4 \%$ & 2 & $22.2 \%$ & 9 & & \\
\hline \multicolumn{10}{|l|}{ Students' family residence } \\
\hline - $\quad$ Rural & 34 & $11.4 \%$ & 140 & $46.8 \%$ & 125 & $41.8 \%$ & 299 & \multirow{2}{*}{16.6} & \multirow{2}{*}{.000} \\
\hline - Urban & 45 & $25.6 \%$ & 64 & $36.4 \%$ & 67 & $38.1 \%$ & 176 & & \\
\hline \multicolumn{10}{|c|}{ Students' residence during current academic year. } \\
\hline - With family & 27 & $15.5 \%$ & 81 & $46.6 \%$ & 66 & $37.9 \%$ & 174 & \multirow{3}{*}{7.489} & \multirow{3}{*}{.891} \\
\hline - University campus & 44 & $18.1 \%$ & 91 & $37.4 \%$ & 108 & $44.4 \%$ & 243 & & \\
\hline - $\quad$ External housing & 8 & $13.8 \%$ & 32 & $55.2 \%$ & 18 & $31.0 \%$ & 58 & & \\
\hline \multicolumn{10}{|c|}{ pre-university qualification } \\
\hline - Secondary school & 72 & $17.7 \%$ & 164 & $40.3 \%$ & 171 & $42.0 \%$ & 407 & \multirow[t]{2}{*}{8.36} & \multirow[t]{2}{*}{.015} \\
\hline $\begin{array}{ll}- & \text { Technical Institute } \\
\text { of Health/Nursing }\end{array}$ & 7 & $10.3 \%$ & 40 & $58.8 \%$ & 21 & $30.9 \%$ & 68 & & \\
\hline \multicolumn{10}{|c|}{ previous academic year achievement } \\
\hline - $\quad$ Excellent & 19 & $20.7 \%$ & 40 & $43.5 \%$ & 33 & $35.9 \%$ & 92 & \multirow[t]{4}{*}{3.07} & \multirow[t]{4}{*}{.808} \\
\hline - $\quad$ Very good & 43 & $16.0 \%$ & 118 & $43.9 \%$ & 108 & $40.1 \%$ & 269 & & \\
\hline - Good & 15 & $14.3 \%$ & 42 & $40.0 \%$ & 48 & $45.7 \%$ & 105 & & \\
\hline - $\quad$ Satisfactory & 2 & $22.2 \%$ & 4 & $44.4 \%$ & 3 & $33.3 \%$ & 9 & & \\
\hline Total & & 79 & & $\overline{44}$ & 19 & & 475 & & \\
\hline
\end{tabular}


Table (3): Multiple regression to identify the most variable that affects on self-esteem .

\begin{tabular}{|l|c|c|c|}
\hline \multicolumn{1}{|c|}{ Personal Data } & Beta & T & Sig. \\
\hline Students' family residence & .104 & 2.272 & .024 \\
\hline Marital status & .062 & 1.356 & .176 \\
\hline Students' residence during current academic year & .033 & .723 & .470 \\
\hline pre-university qualification & .030 & .645 & .519 \\
\hline previous academic year achievement & .080 & 1.738 & .083 \\
\hline
\end{tabular}

Table (1): Demonstrate that the nursing students' age ranged between 20 to 23 years, with $63.8 \%$ being females and single $98.1 \%$. Regarding students' family residence, $62.9 \%$ of the nursing students were from rural areas and 37.1 of them were living in urban areas.

As for residency during academic years, $51.2 \%$ of the students (male \& female) were living in the university campus. Regard their pre-university qualification $85.7 \%$ of nursing students were from secondary school and only $14.3 \%$ were from the technical institute of health or the technical institute of nursing. For their previous academic year achievement noted that, $56.6 \%$ of the nursing students had "very good" grade and $1.9 \%$ of them had "satisfactory" grade.

Figure (1): Illustrates that $43 \%$ of the nursing students had moderate self-esteem, while $41 \%$ had high self-esteem and only $16 \%$ had low self-esteem, with mean and standard deviation of $50.7 \pm 6.11$.

Figure (2): Show that both female nursing students and male nursing students had moderate level of selfesteem (42\% and $43 \%$ ) respectively.

Table (2): Reveals high statistically significant difference between level of "self-esteem" and "family residency" $(p=.000)$, another high statistically significant difference between "self-esteem" and "pre-university qualifications" ( $\mathrm{p}=.015)$. Furthermore, the present study revealed no statistically significant differences between "age" and "self-esteem" $(\mathrm{p}=.339)$, Another no statistically significant difference was found between level of "self-esteem" and "marital status" $(\mathrm{p}=.351)$. Married students had more tendency to have low level of self-esteem $(33.3 \%)$ than single students $(16.3 \%)$, and no statistically significant difference between, "students' residency during academic year" or their gender, $(\mathrm{p}=.891$, and $\mathrm{p}=.920)$ respectively. students from secondary school have high level of self-esteem than Students from the technical institute of health or nursing. There was no statistically significant difference between "self-esteem" and "previous academic achievement" $(\mathrm{p}=.808)$

Table (3): Represents that the best fitting multiple regression model for self-esteem is students' family residence beta was (.104), followed by marital status beta was (.062), then Students' residence during current academic year was (.033), and as for preuniversity qualification beta was (.030) and finally previous academic year achievement beta was (.080).

\section{Discussion}

Self-esteem is a core predictor of subjective wellbeing and life satisfaction, and it is closely related to turnover intention, job burnout, and mental health. (He, et al., 2019).

Individuals with high level of self-esteem can feel a greater sense of self-worth and have a stable personality tendency. (Shrivastava, \& Mishra, 2015).

So the aim of the current was to assess the level of self-esteem among male and female nursing students enrolled in maternity curriculum, at Assiut University.

Main part of particular interest in the present study finding that most levels of maternity nursing students levels of self-esteem was moderate and high among nearly half of them. This finding agree with Ibrahim, (2015), who assessed level of self-esteem among nursing students in Iraq, he found that moderate selfesteem was $45.7 \%$ \& high self-esteem was $39 \%$. And also consistent with Dabirian, \& colleagues, (2016), who assessed the correlation between nurses' selfesteem and job satisfaction in educational hospitals of Khorramabad in Iran, their results were classified as follows; moderate level of self-esteem represented $40.9 \%$ and $41 \%$ have high level of self-esteem level. But the results disagree with the finding of Belsiyal, (2015), who assessed level of self-esteem among B.Sc. nursing students in a selected college of nursing at Bangalore, Karnataka, in India, she reported that two thirds of nursing students have moderate level of self-esteem while one third of them have low level of self-esteem. It also disagree with the finding of Nikitha, \& colleagues., (2014), who assessed academic stress and self-esteem among higher secondary students in selected schools of Udupi district, in India, they found that majority of nursing students have moderate level of self-esteem. This could be explained as that India is considered a developing country, the strict traditions and customs of the society, and also difficulties of life and poverty lead to low level of self-esteem. These differences may be due to differences of communities, cultures 
and attractiveness of students to maternity curriculum.

The current study revealed that both female nursing students and male nursing students had moderate level of self-esteem (42\% and 43\%) respectively, this finding disagree with the finding of Arshad, \& colleagues, (2015), who studied self-esteem and academic performance among university students in Pakistan ,they found that male students had higher self-esteem than female students, this is due to Pakistani society provided males with a lot of privileges than females such as right of education, work and right to choose partner for marriage .

These results also disagree with the finding of Nupur, \& Mahapatro, (2016), who studied gender differences in self-esteem among young adults of Raipur, Uttar Pradesh, in India, they found that males had lower level of self-esteem than females. The explanation of these differences may be due to societal changes in India as now the girls are now getting much more opportunities to step out of the house in order to get educated, develop careers and even make a choice of a suitable partner for marriage. Also the Indian society is improving slowly and steadily in helping women making a difference and achieve equality with the men.

The current study showed a high statistically significant difference between level of "self-esteem" and "family residency, as the students from rural areas have high level of self-esteem this finding agree with the finding of Mulyadia, \& Colleagues, (2016), who assess the role of parent-child relationship, selfesteem, academic self-efficacy to academic stress, in Indonesia. And also in the same side agree with the results of Mogonea, (2014), who assess the role of the family in building adolescents' self-esteem in Romania. This finding disagree with the results of Amalu, (2017), who studied family environment and self-esteem as predictors of psychological adjustment of secondary school students in Nigeria, she found that there was no statistically significant difference between "self-esteem" and "family residency.

These differences could be due to that life in rural area is still holding by their values, parents are concerning to educate their children about their religion, customs and tradition, and on contrary parents in the city are busy to earning their living, and leaving their children for the effect of the internet, social media \& their peers.

Also the present study found a high statistically significant difference between "self-esteem" and "pre-university qualifications, which refer to that the students from secondary school have low level of self-esteem than students from the technical institute of health or nursing, the explanation of this finding may be due to enrollment to the faculty of nursing after graduation from the technical institute of health or nursing considered as an advantage because they have background about nursing curriculum and also the past experience of studying nursing subjects which play a role.

Regarding to family residency, the current results refer that nearly two thirds of the nursing students were from rural areas, which agree with the result of Bhagora, \& colleagues, (2019), who assessed the level of self-esteem among B.SC nursing students with the view to develop and implement counseling session in selected colleges of Udaipur in India they found that $70 \%$ of his sample belong to rural area while only $30 \%$ belongs to urban area.

The present study represents that the main factor affecting self-esteem is students' family residence, according to multiple regression analysis of the data. This finding agree with the finding of Hanafi, \& Colleagues, (2016), who performed a program to enhance self-esteem among nursing students in the faculty of nursing at Mansoura University, in Egypt, they found that the main factor affecting self-esteem is students' family residence. It also agree with the finding of Manomenidis, \& Colleagues., (2017), who assessed relationship between self-esteem \& nursing burnout, in Greece. On the other hand, it disagree with Duruk, \& Colleagues, (2017), who studied the effect of university education on selfesteem, in Turkey, they found that gender is the main factor affecting self-esteem.

The present study revealed that the mean age of maternity nursing students was $20.91 \pm .699$, which in harmony of the study finding of Valizadeh, \& Colleagues, (2016), who assessed self-esteem challenges of nursing students in Iran, they found that the mean age of nursing students was 20.6 years, and nearly similar to respect Watson, \& colleagues, (2017), who studied stressors affecting nursing students in Pakistan. They reported that mean age of the nursing student was 22.3 years, this is due to all college students have similar age in each phase of their study.

As regarding gender, the results noted that about two thirds of maternity nursing students were females and only one third were males. This could be explained by that nursing is a femmin profession, the new admission of male students to the faculty since the academic year of 2013 - 2014, and the lack of community awareness about the admittance of male students to faculty of nursing. This results in the same way agree with all national and international numbers of male in the field of nursing as the ministry of health and population in Egypt reported that men comprised $9.22 \%$ of the registered nursing personnel. While international statistics showed that in Australia, New Zealand, UK and USA, male 
registered nurses account for less than $10 \%$ of the nursing workforce, and in China, male nurses represent less than $1 \%$ of the total workforce. AlMomani, (2017). based on the Organization of men in nursing occupations which mentioned that men comprised $12 \%$ of all nurses in the United States and 9\% of the registered nursing personnel in the United Kingdom Cheng, \& Colleagues, (2018).

Concerning to marital status of students, the vast majority of nursing students were single. This may be related to the concept that marriage may impose a stressor and affect their study, plus the socioeconomic conditions. This results inaccordance with the finding by, Senturk, \& Dogan N., (2018), who studied the determination of the stress experienced by nursing students' during nursing education in Turkey, they reported that vast majority of the nursing students $(98.4 \%)$ were single. And in the same line another study conducted on nursing students in Nigeria by Egwurugwu J N., and colleagues., (2018), who assessed relationship between self-esteem and impostor syndrome among undergraduate medical students in a nigerian university. They found that $88 \%$ of students were single.

In relation to previous academic year achievement, the present study showed that half of students had very good grade and few percent of them had excellent grade. This could be explained by the distinct prerequisite requirement to submit the faculty and the educational approach used in the faculty. This finding agree with Dimitriadou, \& Colleagues, (2014). who studied the concept of self-esteem in nursing education \& its impact on professional behavior, in Greece, they found that $50 \%$ of their sample have very good grade \& $25 \%$ have excellent grade.

\section{Conclusion}

Results of the present study concluded that there were no differences in self-esteem levels between males and females nursing student.

\section{Recommendations}

In the light of the findings of the present study, the following are recommend:

- Counseling center for nursing students in the faculty should be established.

-The nursing curriculum should incorporate activities that help students in developing self-esteem, such as: games, film strips, and self-esteem group activities. -Psychiatric nursing department must act as positive role models in academia and clinical practice.

\section{References}

1. Alavijeh M., Rahimi H., Matin B., Jalilian F., (2018): Self-esteem and academic achievement among students of Kermanshah university of medical sciences. Educ. Res. Med. Sci, Vol. 7, n. (1), PP $1-4$.

2. Al-Momani M., (2017): Difficulties encountered by final-year male nursing students in their internship programmes. Malays J. Med. Sci., Vol. 24, n. (4), PP 30-38.

3. Amalu M., (2017): Family environment and self-esteem as predictors of psychological adjustment of secondary school students from divorced homes in cross river state, Nigeria. Journal of research \& method in education, Vol. 7, n. (6), PP 9-16.

4. Arshad M., Zaidi S., Mahmood K., (2015): Self-esteem \& academic performance among university students. Journal of education and practice, Vol. 6, n. (1), pp 156-162.

5. Belsiyal X., (2015): Level of self-esteem among B.Sc. (N) students in a selected college of nursing at Bangalore, Karnataka. Asian j. nursing edu. and Research, Vol. 5, n. (2), pp 137 -141 .

6. Bhagora H., Kumar S., Hawaibam B., (2019): A study to assess the level of self-esteem among B.SC nursing students with the view to develop and implement counseling session in Selected colleges of Udaipur. International journal of recent scientific research Vol. 10, n. (5), pp 32160-32161.

7. Bialobrzeska O., Parzuchowskia M., Studzinskab A., Barylaa W., Wojciszkea B., (2018): Propensity to take the agent perspective moderates the relative importance of agency versus communion in self-esteem (but only slightly). Personality and individual differences, Vol. 126, PP 71-77.

8. Buthelezi S., Fakude L., Martin P., Daniels F., (2015): Clinical learning experiences of male nursing students in a bachelor of nursing programme. Curationis, vol.38, n. (2), PP $1-7$.

9. Cheng M., Tseng Y., Hodges E., Chou F, (2018): Lived Experiences of Novice Male Nurses in Taiwan, Journal of Transcultural Nursing, Vol. 29, n. (1), pp 46-53

10. D'Mello L., Monteiro M., Pinto N., (2018): A study on the self-esteem and academic performance among the students. International journal of health sciences and pharmacy, Vol. 2, n. (1), PP 1- 7.

11. Dabirian A., Malekipour S., Kakhki A., Mehrabi Y., (2016): The correlation between nurses' self-esteem and job satisfaction in educational hospitals of Khorramabad in 2014. 
Advances in nursing \& midwifery, Vol. 25, n. (88), pp 1- 6

12. Dimitriadou A., Koukourikos K., Pizirtzidou E., (2014): The concept of self-esteem in nursing education and its impact on professional behavior. International journal of caring science, vol. 7, no. (1), PP 6- 11.

13. Duruk N., Kurban N., Kurban O., (2017): An example of nursing students' self-esteem: does university education make a difference? International journal of caring sciences, Vol. 10, no. (3), PP 1577- 1586.

14. Egwurugwu J., Ugwuezumba P., Ohamaeme M., Dike E., Eberendu I., Egwurugwu E., Ohamaeme R., Egwurugwu U., (2018): Relationship between self-esteem and impostor syndrome among undergraduate medical students in a Nigerian university. International journal of brain and cognitive sciences, $\operatorname{Vol} 7, \mathrm{n}$. (1), pp 9-16.

15. El-Desouki M., (2004). Self Esteem Scale. AlAnglo Egyptian Library, Cairo. 16051.

16. Farhan S., \& Khan I., (2015): Impact of stress, self-esteem \& gender factor on students academic achievement. International journal on new trends in education and their implications, Vol 6, n. (2), PP143- 156.

17. Hanafi S., EL-bilsha M., Khater M., (2016): A program to enhance self-esteem among nursing students in the faculty of nursing at Mansoura university. Med. J. Cairo Univ., Vol. 84, n. (1), PP 57- 63.

18. Hank P., \& Baltes-Götz B., (2019): The stability of self-esteem variability: A real-time assessment. Journal of research in personality, Vol. 79, PP 143-150.

19. He L., Maa Y., Zhangb K., Wanga Y., (2019): Self-esteem enhancement as a strategy for promoting the mental health and averting the occupational problems of nurses. Frontiers of nursing, Vol 6, n. (1), PP 59-65.

20. Ibrahim R., (2015): Assessment of self-esteem among nursing students. Journal of health, medicine and nursing, Vol.16, pp 34- 37.

21. Manomenidis G., Kafkia T., Minasidou E., Tasoulis C., Koutra S., Kospantsidou A., Dimitriadou A., (2017): Is self-esteem actually the protective factor of nursing burnout. International journal of caring sciences, Vol. 10, n. (3), PP 1348 - 1359.

22. McCarthya B., Traceb A., O'Donovan M., Brady-Nevina C., Murphyd M., O'Sheae M., O'Regana P., (2018): Nursing and midwifery students' stress and coping during their undergraduate education programmes: an integrative review. Nurse education today, Vol. 61, PP 197-209.

23. Mogonea F., (2014): The role of the family in building adolescents' self-esteem. Procedia Social and Behavioral Sciences, Vol. 127, pp $189-193$.

24. Mulyadia S., Rahardjoa W., Basukia A., (2016): The role of parent-child relationship, self-esteem, academic self-efficacy to academic stress. Procedia - social and behavioral sciences, Vol.217, pp $603-608$.

25. Nikitha S., Jose T., Valsaraj B., (2014): A correlational study on academic stress and selfesteem among higher secondary students in selected schools of Udupi district. Nitte university journal of health science, Vol. 4, n. (1), pp $106-108$.

26. Nupur C., \& Mahapatro M., (2016): Gender differences in self-esteem among young adults of Raipur, Uttar Pradesh, India. Austin J. women's health, Vol. 3, n. (1), pp 1-4.

27. Orth U., Erol Y., Luciano C., (2018): Development of self-esteem from age 4 to 94 years: a meta-analysis of longitudinal studies. Psychological bulletin, Vol 144, PP 1045-1080.

28. Senturk S., Dogan N., (2017): Determination of the Stress experienced by nursing students' during nursing education. International journal of caring sciences Vol 11, n. (2), pp 896 - 904.

29. Shrivastava U., \& Mishra V., (2015): Effect of self-esteem enhancement on assertiveness of school students. The international journal of Indian psychology, Vol. 3, n. (1), PP 1-9.

30. Silvestri P., Baglioni V., Cardona F., Cavanna A., (2018): Self-concept and selfesteem in patients with chronic tic disorders: systematic literature review. European journal of paediatric neurology. PP $749-756$.

31. Teng Z., Liu Y., Guoa C., (2015): A metaanalysis of the relationship between self-esteem and aggression among Chinese students. Aggression and violent behavior, Vol. 21, PP 45-54.

32. Valizadeh L., Zamanzadeh V., Badri R., Ghahramanian A., Jabbarzadeh F, Keogh B., (2016): Self-esteem challenges of nursing students: an integrative review. Res. Dev. Med. Educ., Vol.5, n. (1), pp 5-11.

33. Velmurugan K., Balamurugan G., Vijayarani M., (2018): Self-esteem among nursing students. A journal of health professions, Vol. 8, no (1) PP 13-15.

34. Von Soest T., Wichstrøm L., \& Kvalem L., (2016): The development of global and domainspecific self-esteem from age 13 to 31 . Journal of personality and social psychology, PP1-57. 
35. Watson R., Rehman S., Ali P., (2017): Stressors affecting nursing students in Pakistan. International nursing review, pp 1-22.

36. Zamanzadeh V., Valizadeh L., Gargari R., Akram, Ghahramanian A., Tabrizi F., Crowley M., (2016): Nursing students understanding of the concept of self-esteem. Journal of caring sciences, Vol. 5, no (1), PP 3341. 